\title{
Fried pork loin batter quality with the addition of various dietary fibers
}

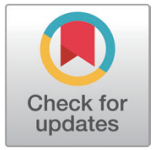

Received: Aug 19, 2020

Revised: Oct 16, 2020

Accepted: Nov 7, 2020

${ }^{*}$ Corresponding author

Hack-Youn Kim

Department of Animal Resources

Science, Kongju National University,

Chungnam 32439, Korea.

Tel: +82-41-330-1241

E-mail: kimhy@kongju.ac.kr

Copyright $@ 2021$ Korean Society of Animal Sciences and Technology.

This is an Open Access article distributed under the terms of the Creative Commons Attribution Non-Commercial License (http:// creativecommons.org/licenses/by$\mathrm{nc} / 4.0 /$ ) which permits unrestricted non-commercial use, distribution, and reproduction in any medium, provided the original work is properly cited.

ORCID

Sin-Young Park

https://orcid.org/0000-0001-7900-5987

Hack-Youn Kim

https://orcid.org/0000-0001-5303-4595

\section{Competing interests}

No potential conflict of interest relevant to this article was reported.

Funding sources

This work was carried out with the support of "Cooperative Research Program for Agriculture Science \& Technology Development (Project No.PJ01528103)" Rural Development Administration, Korea.

Acknowledgements Not applicable.

Availability of data and material Upon reasonable request, the datasets of this study can be available from the corresponding author.

\author{
Sin-Young Park and Hack-Youn Kim* \\ Department of Animal Resources Science, Kongju National University, Chungnam 32439, Korea
}

\begin{abstract}
The effect of the addition of dietary fiber extracted from wheat, bamboo, and oat on the quality of fried pork loin batter was investigated. Quality evaluation included proximate composition, $\mathrm{pH}$, color, viscosity, coating and frying yield, electronic nose, and sensory evaluation. Regarding proximate composition of fried batter and fried pork loin, the water content of the dietary fiber treatments was significantly higher than that of the control $(p<0.05)$, whereas fat content was significantly lower than that of the control $(p<0.05)$. The lightness of non-fried batter with dietary fiber treatments was significantly higher than that of the control $(p<0.05)$, whereas the yellowness was significantly lower than that of the control $(p<0.05)$. The lightness, redness, and yellowness of fried pork loin with dietary fiber treatment were significantly lower than those of the control $(p<0.05)$. The viscosity and coating and frying yield of dietary fiber treatments were significantly higher than those of the control $(p<0.05)$. The volatile compounds of dietary fiber treatments were decreased "tallowy" flavor and increased "buttery" and "milky" flavor. The principal components of bamboo and oat fiber treatments were clearly distinguishable from those of the control; however, similar principal components as those of the control were obtained with wheat fiber treatment. Regarding sensory evaluation, the color, texture, and overall acceptability of wheat and oat fiber treatments were significantly higher than those of the control $(p<0.05)$, and the flavor of the wheat fiber treatment was significantly higher than that of the control $(p<0.05)$. These results show that wheat and oat fibers are suitable for fried pork loin batter and improve its quality.
\end{abstract}

Keywords: Batter, Deep-frying, Dietary fiber, Pork loin, Quality properties

\section{INTRODUCTION}

Current trends in the supply and demand of animal-based products, including meat-based products, have been steadily increasing and this has also lead to an increase in public health concerns regarding meat or meat-based product consumption [1]. Concerns over edible oils and fats contained in meatbased products that have undergone the deep-fat frying processes are especially high [2], and such dishes are publicly perceived as one of the culprits of high blood pressure and obesity in adults $[3,4]$.

Deep-fat frying requires submerging ingredients in edible oils and fats, typically heated to $140^{\circ} \mathrm{C}-190^{\circ} \mathrm{C}$, for several minutes depending on the ingredients used and the recipe. This process traps moisture and absorb oils to enhance the flavor [5]. The most commonly used method is to coat batter 
Authors' contributions Conceptualization: Kim HY.

Data curation: Kim HY.

Formal analysis: Park SY.

Methodology: Kim HY.

Software: Park SY.

Validation: Kim HY.

Investigation: Park SY.

Writing - original draft: Park SY.

Writing - review \& editing: Park SY, Kim HY.

Ethics approval and consent to participate The sensory evaluation was approved by the Kongju National University's Ethics Committee (Authority No: KNU IRB_202040). on the surface of a piece of meat base before frying in oil [4]. The batter quickly solidifies from its original fluid consistency, becoming a protective coat holding the moisture and flavor of the base ingredient while allowing oil to be better absorbed to enhance the flavor [6]. However, this process raises trans-fat content excessively leading to higher health risks in adults $[7,8]$. Therefore, there is an urgent need for fried-food development and production that takes into consideration and supports consumer health.

Dietary fibers, also known as fiber or cellulose, do not undergo digestion in the human digestive system and are excreted from the body as carbohydrate macromolecules [9]. When ingested through edible means, dietary fibers can absorb water and toxins effectively from the gastrointestinal tract and protect the organs from damage through absorption of the trapped toxic compounds while promoting active bowel movement. They can also attenuate fat absorption within the gastrointestinal tract, lowering blood cholesterol levels and risks of cardiovascular diseases [10,11]. These properties of dietary fibers, in addition to being a strong emulsifying agent, allow diverse applications in commercial industry, namely as adhesives or extenders for liquid or semi-solid food products [11]. When the emulsifying capacity is improved, the viscosity also increases, preventing the batter from dripping down during the batter coating process and coating the meat more stably [12]. Thus, adding dietary fiber to the batter can improve the physical quality of the batter.

The loin cut (musculus longissimus dorsi) is known to have low-fat and high protein content among diverse pork cuts and is the commonly used ingredient in various deep-fried pork recipes [13]. Therefore, this study aimed to treat deep-fat frying batter with dietary fibers extracted from wheat, bamboo, and oat, and evaluate the effects on the quality of the batter and the applicability of dietary fibers in pork-based fried products.

\section{MATERIALS AND METHODS}

\section{Fried pork loin preparation}

In this study, fried pork loin was prepared using the, slightly modified methods of Fiszman and Sanz [6] and Adedeji and Ngadi [14]. Ingredients used for the pork loin batter are shown in Table 1

Table 1. Ingredient of batter for fried pork loin formulated with various type of dietary fiber

\begin{tabular}{lcccc}
\hline \multirow{2}{*}{ Ingredients (\%) } & \multicolumn{5}{c}{ Treatment } \\
\cline { 2 - 5 } & Control & WF & BF & OF \\
\hline Milk & 53 & 53 & 53 & 53 \\
Whole eggs & 12.5 & 12.5 & 12.5 & 12.5 \\
Wheat flour & 15 & 15 & 15 & 15 \\
Corn flour & 11 & 11 & 11 & 11 \\
Rice flour & 2 & 2 & 2 & 2 \\
Corn starch & 2 & 2 & 2 & 2 \\
Salt & 1 & 1 & 1 & 1 \\
Sugar & 0.8 & 0.8 & 0.8 & 0.8 \\
Baking powder & 0.3 & 0.3 & 0.3 & 0.3 \\
Black pepper powder & 0.2 & 0.2 & 0.2 & 0.2 \\
Wheat fiber & - & 3 & - & - \\
Bamboo fiber & - & - & 3 & - \\
Oat fiber & - & - & - & 3 \\
\hline
\end{tabular}

Control, batter without dietary fiber; WF, batter with wheat dietary fiber; BF, batter with bamboo dietary fiber; OF, batter with oat dietary fiber. 
along with the inclusion of different dietary fibers (3\%) for each sample. Samples were subjected to one of the following dietary fiber treatments: wheat fiber (WF; extracted and isolated from wheat bran; Vitacel WF 200, JRS, Rosenberg, Germany; 97\% dietary fiber content and 3\% oxide ash), bamboo fiber (BF; extracted and isolated from bamboo-shoot; Vitacel BAF 200, JRS; 96\% dietary fiber content and $0.5 \%$ oxide ash), or oat fiber (OF; extracted and isolated from oat bran; Vitacel HF 200, JRS; 97\% dietary fiber content and 3\% oxide ash). To manufacture the batter mixture, all ingredients were mixed appropriately; then, the pork loin was cut into $1.5 \times 6 \times 1 \mathrm{~cm}$ (length $\times$ width $\times$ height) pieces, dipped into the batter mixture for $30 \mathrm{~s}$, and hung for $25 \mathrm{~s}$. After preparation, the pieces were deep-fried in soybean oil for $3 \mathrm{~min}$ at $180^{\circ} \mathrm{C}$. The fried pork loin samples were cooled at $20^{\circ} \mathrm{C}$ for $30 \mathrm{~min}$.

\section{Proximate composition}

The proximate composition of fried batter without pork loin and fried batter with pork loin were measured using the following methods according to AOAC protocols [15]. Moisture content was measured using the oven-drying method, crude protein content was measured with the Kjeldahl method, crude fat content was measured with the Soxhlet method, and ash content was measured using the dry ashing method.

$\mathrm{pH}$

To measure the $\mathrm{pH}$ of non-fried batter without pork loin and fried batter with pork loin samples, $4 \mathrm{~g}$ of each sample was homogenized in $16 \mathrm{~mL}$ distilled water using an Ultra-Turrax homogenizer (HMZ-20DN, Poolim Tech., Seoul, Korea) at 10,923×g for $1 \mathrm{~min}$. After sample preparation, the $\mathrm{pH}$ was measured using a pH meter (Model S220, Mettler-Toledo, Schwerzenbach, Switzerland).

Color

The CIE general colors of non-fried batter without pork loin and fried batter with pork loin were measured using a colorimeter (CR-10, Minolta, Tokyo, Japan), and the lightness ( $\left.\mathrm{L}^{*}\right)$, redness ( $\left.\mathrm{a}^{*}\right)$, and yellowness $\left(b^{*}\right)$ were evaluated. A white standard plate (CIE L* ${ }^{*}+97.83$; CIE a*,-0.43 ; CIE $b^{*}$, $+1.98)$ was used as the reference.

\section{Viscosity}

The viscosity of the non-fried batter without pork loin samples, was measured using a rotational viscometer (Merlin VR, Rheosys, Hamilton Township, NJ, USA). The viscometer was attached to $30 \mathrm{~mm}$ cone, and the sample was placed in a $25 \mathrm{~mm}$ co-axial cylinder. Measurements were conducted for $60 \mathrm{~s}$ at $20^{\circ} \mathrm{C}$ with a head speed of $20 \mathrm{rpm}$. Measured values were calculated as the average and reported as Pa.s.

\section{Coating yield}

The coating yield was analyzed using the, slightly modified, method of Adedeji and Ngadi [14]. The batter coating of pork loin samples was determined by calculating the difference in pork loin weight before dipping and after hanging as follows:

$$
\text { Coating yield }(\%)=\frac{\text { Weight after hanging }(\mathrm{g})}{\text { Weight before dipping }(\mathrm{g})} \times 100
$$

\section{Frying yield}

The frying yield of batter with pork loin samples was calculated from pork loin using batter weight 
before and after frying.

$$
\text { Frying yield }(\%)=\frac{\text { Weight after frying }(\mathrm{g})}{\text { Weight before frying }(\mathrm{g})} \times 100
$$

\section{Electronic nose}

Aroma profiling of fried batter with pork loin samples was performed using a Heracles II electronic nose (Alpha MOS, Toulouse, France). The electronic nose analysis conditions were as follows: $1 \mathrm{~g}$ of sample was weighed in a $20 \mathrm{~mL}$ vial; flow rate, $250 \mathrm{~mL} / \mathrm{min}$; acquisition time, $120 \mathrm{~s}$; headspace temperature, $60^{\circ} \mathrm{C}$; quantity injected, $2.5 \mathrm{~mL}$. Before performing the principal component analysis (PCA), the sensitivity of each electronic nose sensor was measured to determine the rate of change between the resistance values of the volatile compound and the air. These measured sensitivity values were analyzed using Alpha software program (Alpha MOS, Toulouse, France) for the PCA procedure. The classified aroma pattern was reported as the primary component value (PC1) and secondary component value (PC2).

\section{Sensory evaluation}

Sensory evaluations of fried batter with pork loin samples were performed in triplicate with 10 sensory panelists. The panelists used basic taste identification tests and were trained with pork loin coated in a commercial batter mix for 7 days ( $1 \mathrm{~h}$ sessions per day) to familiarize themselves with the fried pork loin sensory properties to be evaluated. The color, flavor, texture, juiciness, off-flavor, and overall acceptability (1, extremely undesirable; 10 , extremely desirable) of the samples were evaluated based on a 10-point descriptive scale.

\section{Statistical analysis}

All analyses except electronic nose results were assessed after a minimum of triplicate trials. Variances among all variables were analyzed using the analysis of variance and the general linear model in SAS version 9.3 (SAS Institute, Cary, NC, USA), and the Duncan's multiple range test was performed for verifying the significances of differences observed $(p<0.05)$, and the data were presented as mean and SEM.

\section{RESULTS AND DISCUSSION}

\section{Proximate composition}

Recently, many consumers who pursue a healthy lifestyle have raised concerns over excessive fat consumption through deep-fat fried foods [4]. Therefore, evaluation of the proximate composition of material involved in food development and production is critical, and meat-based products need to satisfy the consumer demand for the manufacture of products that address their relevant health concerns [16]. As an additive, dietary fiber has an excellent ability to absorb water and expel fat $[9,17,18]$. Table 2 shows the effects of the addition of different dietary fiber types on the proximate composition of fried batter and fried batter with pork loin. The moisture content of the fried batter was significantly higher in all dietary fiber treatments than that in the control $(p<0.05)$. WF and $\mathrm{BF}$ treatments did not differ significantly from each other; however, the OF treatment showed significantly lower moisture content than the $\mathrm{BF}$ group $(p<0.05)$. In contrast, the fat content was significantly lower in dietary fiber-treated groups than that in the control $(p<0.05)$. Ash content was also significantly lower in the control than that in WF or BF treatments $(p<0.05)$. Overall, there were no significant differences observed between the dietary fiber treatment groups for ash 
Table 2. Proximate composition of fried batter and fried batter with pork loin formulated with various type of dietary fiber

\begin{tabular}{|c|c|c|c|c|c|}
\hline \multirow{2}{*}{ Traits } & \multicolumn{4}{|c|}{ Treatment } & \multirow{2}{*}{ SEM } \\
\hline & Control & WF & BF & OF & \\
\hline \multicolumn{6}{|l|}{ Fried batter (\%) } \\
\hline Water & $14.06^{\mathrm{c}}$ & $30.02^{\mathrm{ab}}$ & $32.94^{\mathrm{a}}$ & $26.75^{\mathrm{b}}$ & 2.23 \\
\hline Protein & 5.79 & 5.66 & 6.20 & 6.15 & 3.80 \\
\hline Fat & $49.70^{\mathrm{a}}$ & $25.66^{b}$ & $15.64^{\mathrm{c}}$ & $28.70^{\mathrm{b}}$ & 0.10 \\
\hline Ash & $1.69^{b}$ & $1.97^{\mathrm{a}}$ & $2.04^{\mathrm{a}}$ & $1.86^{\mathrm{ab}}$ & 0.05 \\
\hline \multicolumn{6}{|c|}{ Fried batter with pork loin (\%) } \\
\hline Water & $48.47^{b}$ & $56.97^{\mathrm{a}}$ & $56.35^{\mathrm{a}}$ & $55.81^{\mathrm{a}}$ & 0.87 \\
\hline Protein & 25.04 & 23.09 & 24.49 & 24.89 & 0.25 \\
\hline Fat & $7.94^{\mathrm{a}}$ & $6.21^{b}$ & $6.75^{\mathrm{b}}$ & $6.08^{\mathrm{b}}$ & 0.54 \\
\hline Ash & 1.55 & 1.56 & 1.62 & 1.54 & 0.02 \\
\hline
\end{tabular}

All data shown as mean.

${ }^{a-c}$ Means on the same row with different letters are significantly different $(p<0.05)$

Control, batter without dietary fiber; WF, batter with wheat dietary fiber; BF, batter with bamboo dietary fiber; OF, batter with oat dietary fiber.

and protein content. However, dietary fiber treatments had significantly higher water content $(p<$ $0.05)$ but lower fat content $(p<0.05)$ than those of the control. All dietary fiber treatment groups had high water and low-fat composition for both fried batter and fried pork loin compared to that of the control. A similar study also reported decreased fat and increased moisture content in deep fry batters with the addition of oat, soy, pea, or sugar beet fibers [19]. Therefore, dietary fiber supplementation may prevent absorption of oil from the fried batter coating during the deep-frying process, and this finding can contribute to the development of a product that addresses the health concerns of the modern consumer.

\section{$\mathrm{pH}$ and color}

The water holding capacity of meat products is highly influenced by $\mathrm{pH}$, and the closer $\mathrm{pH}$ is to the isoelectric point (approximately pH 5.0-5.2), the lower the water holding capacity and its quality deterioration [20]. Table 3 shows the effects of added dietary fiber on the $\mathrm{pH}$ of the nonfried batter and fried batter with pork loin. The $\mathrm{pH}$ and color of the batter and batter-coated pork loin after frying are reported in Table 3. Neither before nor after frying did the two groups show significant differences in $\mathrm{pH}$ from the control values. Previous research has established that the degree of $\mathrm{pH}$ change caused by fiber treatment depends on the fiber's intrinsic $\mathrm{pH}$ and the amount added to the batter [21]. However, Choi et al. [22] reported that adding fibers extracted from makgeoli lees had no effect on the $\mathrm{pH}$ of the meat batter. These $\mathrm{pH}$ changes are affected by both the ingredient and the properties of the dietary fiber. The dietary fibers used in this study have a $\mathrm{pH}$ ranging between 6-8 and were expected to have no effect on the uncooked batter.

Dietary fibers are often used to enhance the quality of meat products and, as in this study, they can be applied for chromaticity purposes [3]. Accordingly, the CIE color was measured to determine the effects of adding dietary fiber to the batter on the color of non-fried batter and fried batter with pork loin (Table 3). After evaluating the color of the batter before and after frying, it was seen that the lightness of the control was significantly lower than that of the fibersupplemented experimental groups $(p<0.05)$. The lightness increased in the order of WF > OF $>\mathrm{BF}(p<0.05)$. Redness remained similar across all groups, whereas yellowness was found to be significantly higher for the control than the fiber-supplemented experimental groups $(p<0.05)$. 
Table 3. $\mathrm{pH}$ and color of non-fried batter and fried pork loin formulated with various type of dietary fiber

\begin{tabular}{|c|c|c|c|c|c|}
\hline \multirow{2}{*}{ Traits } & \multicolumn{4}{|c|}{ Treatment } & \multirow{2}{*}{ SEM } \\
\hline & Control & WF & BF & OF & \\
\hline \multicolumn{6}{|l|}{ Non-fried batter } \\
\hline $\mathrm{pH}$ & 7.64 & 7.62 & 7.65 & 7.65 & 0.01 \\
\hline Lightness $\left(L^{*}\right)$ & $73.12^{d}$ & $74.02^{\mathrm{c}}$ & $75.26^{a}$ & $74.50^{b}$ & 0.16 \\
\hline Redness $\left(a^{*}\right)$ & 3.42 & 3.40 & 3.30 & 3.32 & 0.03 \\
\hline Yellowness (b*) & $19.66^{a}$ & $18.36^{\mathrm{c}}$ & $18.12^{\mathrm{C}}$ & $18.76^{\mathrm{b}}$ & 0.15 \\
\hline \multicolumn{6}{|l|}{ Fried pork loin } \\
\hline $\mathrm{pH}$ & 5.88 & 5.98 & 6.04 & 6.07 & 0.01 \\
\hline Lightness $\left(L^{*}\right)$ & $50.20^{\mathrm{a}}$ & $46.98^{b}$ & $45.48^{\mathrm{bc}}$ & $45.34^{c}$ & 0.64 \\
\hline Redness $\left(a^{*}\right)$ & $15.88^{\mathrm{a}}$ & $11.66^{\mathrm{c}}$ & $14.40^{\mathrm{b}}$ & $7.56^{\mathrm{d}}$ & 0.74 \\
\hline Yellowness $\left(b^{\star}\right)$ & $33.46^{a}$ & $22.02^{c}$ & $27.02^{\mathrm{b}}$ & $15.18^{d}$ & 1.55 \\
\hline \multicolumn{6}{|l|}{ All data shown as mean. } \\
\hline
\end{tabular}

Moreover, among the dietary fiber treatment groups, yellowness in $\mathrm{WF}$ and $\mathrm{BF}$ was significantly lower than that in OF $(p<0.05)$. Color changes and differences between dietary fiber-treated groups seen before cooking may vary according to the types of fiber added; therefore, the change is attributed to the intrinsic differences in color between the fiber types (WF: $\mathrm{L}^{*} 87.88, \mathrm{a}^{*} 1.78$, b* 9.34; BF: L* 91.56, a* 1.60, b* 8.42; OF L* 89.12, a* 1.82, b* 9.78). In a similar study, Sosulski and $\mathrm{Wu}$ [23] added pea fiber to bread dough, which is a semi-solid similar to the batter used in our study, and observed increased lightness and yellowness. Additionally, Choi et al. [24] observed similar color changes with the addition of tiger nut fiber to pork burger batter. Fried pork loin control groups tended to have a higher color saturation, lightness, redness, and yellowness than the experimental fiber-treated groups $(p<0.05)$. For lightness, the BF group did not show a significant difference from the other experimental groups; however, the OF group had a significantly lower lightness than that of the WF group $(p<0.05)$. Moreover, the redness and the yellowness of the BF group showed a significantly higher reading than that of either the WF or OF groups $(p<0.05)$, whereas the WF group showed a significantly higher reading than that of the OF group $(p<0.05)$. However, previous research has recorded a golden yellow fried coating rather than the typical dark brown often seen in fried foods among fiber-treated groups [19]. Additionally, when using a brown rice-based dietary fiber, both the lightness and the redness decreased significantly [24]. Therefore, the difference in color changes seen in this experiment compared to those reported in previous studies, despite the similar methodology, is likely caused by the physical properties of the dietary fibers themselves. The lower lightness and redness seen in dietary fiber treatment groups than those of the control group is most likely caused by the Maillard reaction [25], known to occur in the dehydration or heating process of fibers. This phenomenon also explains the higher degree of color change seen with wheat, oat, and bamboo dietary fiber-treated groups than that in the control.

\section{Viscosity, coating yield, and frying yield}

High-viscosity batters can maintain a stable shape during frying [26] and prevent runoff from uncooked meat, leading to higher yield [27]. Dietary fiber has a high water absorption ability, which can improve emulsifying capacity, thereby improving viscosity [12]. Fig. 1 shows the results of uncooked batter viscosity per dietary fiber treatment type. Compared to the control, all dietary fiber-treated groups had significantly higher viscosity $(p<0.05)$, in the increasing order of WF 


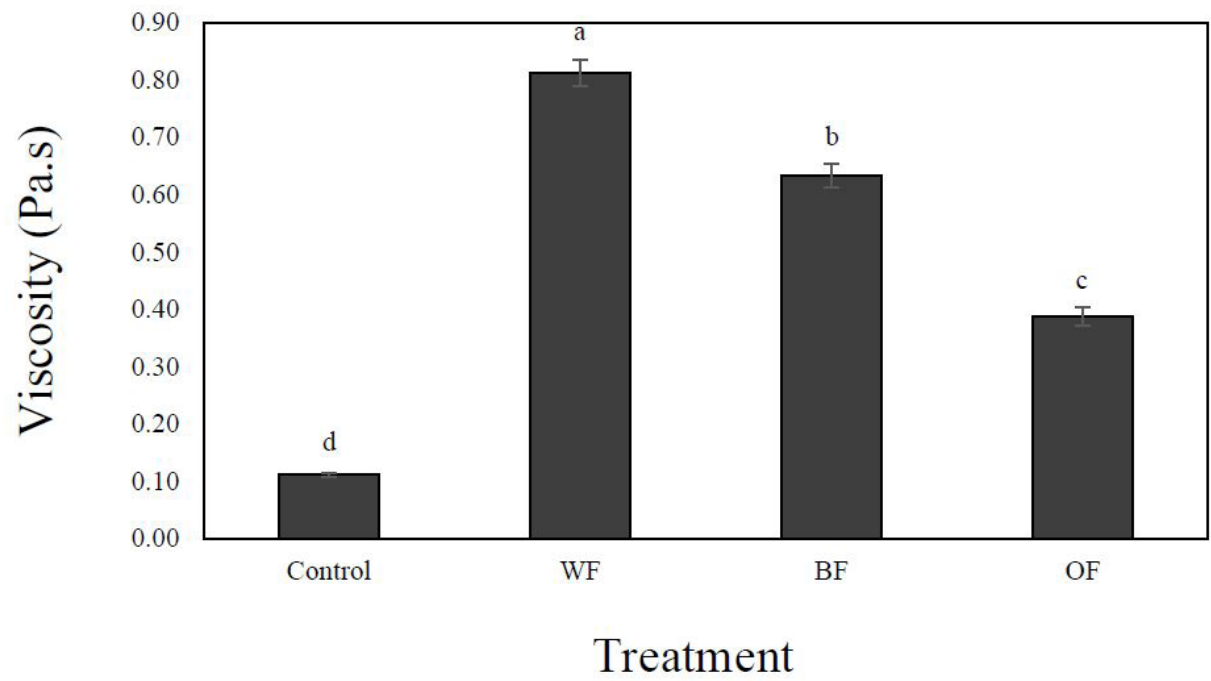

Fig. 1. Viscosity of non-fried batter formulated with various type of dietary fiber. ${ }^{a-d}$ Means on the same bar with different letters are significantly different $(p<0.05)$. Control, batter without dietary fiber; WF, batter with wheat dietary fiber; BF, batter with bamboo dietary fiber; OF, batter with oat dietary fiber.

$>\mathrm{BF}>\mathrm{OF}(p<0.05)$. leading to higher yield [25]. Therefore, fiber-treated groups that showed a 3 -fold increase in viscosity are also expected to allow for a consistent, stable fried product.

The batter coating yields for pork loin and frying yields of batter with pork loin are presented in Fig. 2. Coating yield was significantly higher in the experimental groups than that in the control $(p<0.05)$, and among the fiber-treated groups, $\mathrm{WF}$ and $\mathrm{OF}$ had significantly higher yield than $\mathrm{BF}$ $(p<0.05)$. Similar to the coating yield, frying yield showed a significantly high value for all dietaryfiber treated groups $(p<0.05)$. Coating yield and run-off have an inverse relationship, meaning high viscosity batters have lower batter run-offs and loss [28]. Generally, additional materials like gum or

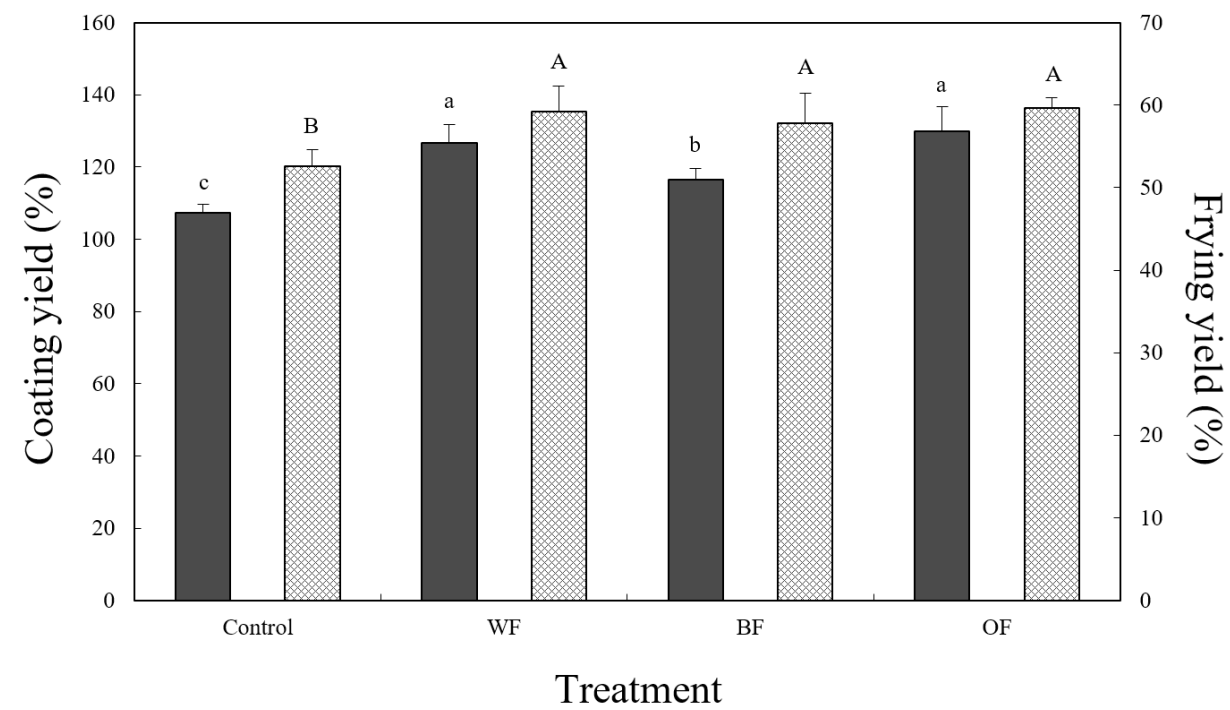

Fig. 2. Batter coating yield for pork loin and frying yield of batter with pork loin formulated with various type of dietary fiber. ${ }^{a-c, A, B}$ Means on the same bar with different letters are significantly different $(p<0.05)$. Control, batter without dietary fiber; WF, batter with wheat dietary fiber; BF, batter with bamboo dietary fiber; OF, batter with oat dietary fiber. 
soy flour are used in commercially prepared batters to increase fried pork frying yield [29,30]. Sahin et al. [31] claimed that by adding xanthan gum and guar gum to the batter, it reduced oil absorption while increasing batter viscosity, leading to a higher proportion of coating pick-up. These results demonstrate the potential of fibers as thickening agents. Like the coating yield, frying yield was also found to be higher in the dietary fiber-treated groups owing to the viscous batter that increased coating stability during the frying process [32]. Therefore, from a commercial perspective, dietary fibers have high potential in producing excellent fried products in the food industry.

\section{Electronic nose}

Dietary fiber exhibits different characteristics and flavors depending on the extracted raw materials [32]. Fig. 3 shows the elution results of fried batter with pork loin over the retention time and the corresponding volatile compounds for each intensity peak. The eluted volatile compounds also included compounds associated with flavor and were identified as methanethiol, dimethyl sulfide, pent-1-en-3-ol, 2,3,-pentanedione, pyrrole, and hexanal. Among these identified compounds, all experimental fiber-treated groups had reduced 2,3-pentanedione and hexanal, associated with "caramelized" and "tallowy" flavors, respectively. However, the pent-1-en-3-ol compound, which simulates a "buttery" and "milky" taste, was increased. Therefore, it can be inferred that the greasy flavor decreased, and the savory flavor increased. Fig. 4 shows the PCA plot of the volatile compounds eluted from the fiber-treated, fried pork loin. In the PCA plot, PC1 ( $x$-axis) and PC2 (y-axis) coordinate representing the properties of the flavor of the sample, and the similarity of flavor can be verified according to the coordinate of the samples [33]. While the BF and OF treatments showed a clear difference in the flavoring components from those of the control, WF shared a relatively similar flavor trait with that of the control. Therefore, WF is expected to have the closest flavor to that of the control compared to BF and OF. In a similar study, Thomas et al. [34] found that treatment with bamboo shoot fiber enhanced the flavor of pork nuggets owing to the nature of the raw ingredient that produces flavor-associated byproducts during the process of fiber extraction [35]. Thus, the similar flavors between wheat fiber treatment and the control can be explained by the flour that takes up a large proportion of the batter ingredient which possesses similar flavor properties with those of the wheat fiber.

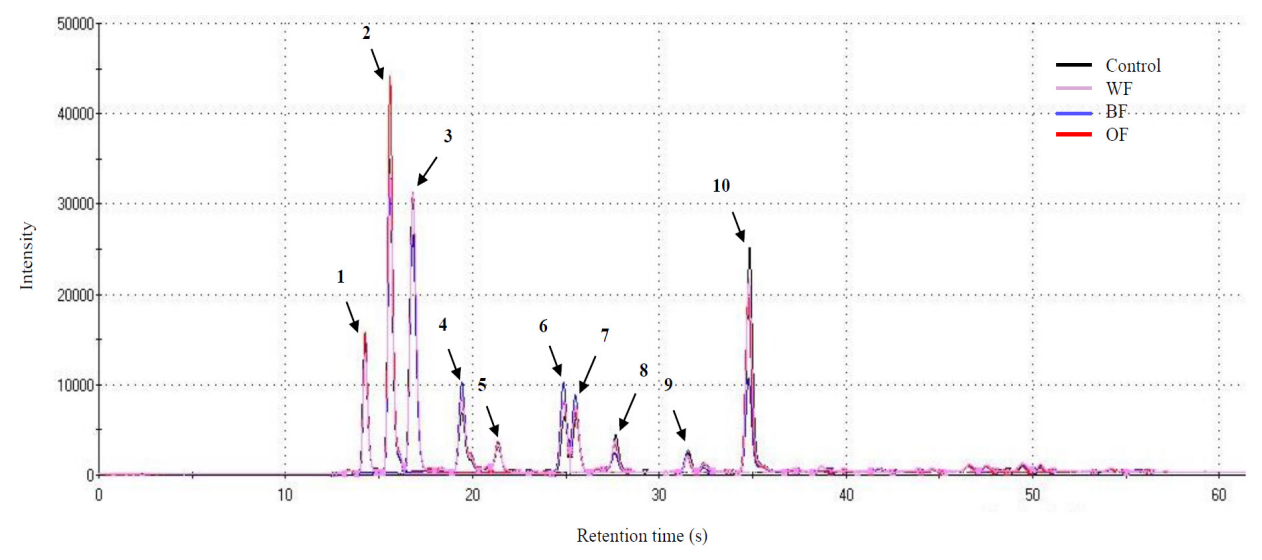

Fig. 3. Volatile compounds of fried batter with pork loin formulated with various type of dietary fiber. Peaks are reported in order of elution: 1 , acetaldehyde; 2 , propenal; 3 , dimethyl sulfide; 4, ethane, 1,1-dichloro-; 5, 2-butanol; 6, pent-1-en-3-ol; 7, pentan-2-one; 8, 2,3-pentanedione; 9, pyrrole; 10, hexanal. Control, batter without dietary fiber; WF, batter with wheat dietary fiber; BF, batter with bamboo dietary fiber; OF, batter with oat dietary fiber. 


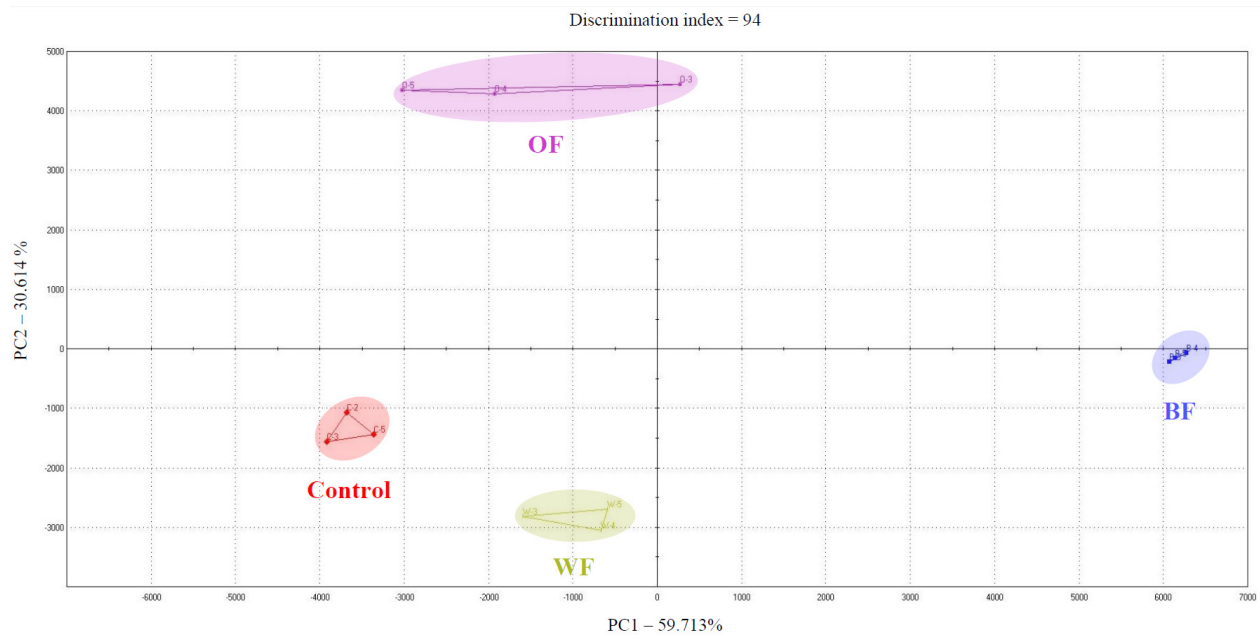

Fig. 4. Principal component analysis plot of battered and fried pork loin formulated with various type of dietary fiber. Control, batter without dietary fiber; WF, batter with wheat dietary fiber; BF, batter with bamboo dietary fiber; OF, batter with oat dietary fiber.

\section{Sensory evaluation}

The sensory evaluation results for fried pork loin are shown in Table 4, and significant differences between the dietary fiber-treated groups are presented in all traits except for off-flavor. Although the color and texture evaluation showed that these values for the WF and OF groups were significantly higher than those of the control $(p<0.05)$, the BF showed no significant difference from the control. Evaluation of the flavor trait showed that WF is significantly higher $(p<0.05)$ than that of the control, but BF and OF had no significant difference from control. The juiciness did not show significant difference between the control and experimental groups; however, juiciness of the $\mathrm{BF}$ was significantly lower than that of the WF and OF groups $(p<0.05)$. The overall acceptability was significantly higher for $\mathrm{WF}$ and $\mathrm{OF}$ treatments than for control and $\mathrm{BF}$ treatment $(p<0.05)$. Therefore, WF and OF, which were highly rated for most traits, are expected to be useful in the development of products that satisfy the sensory properties. Dietary fiber is useful for not only in its health benefits but also as a quality enhancer to enhance solubility, viscosity, and gel formation in a variety of meat products [11], which also enhances sensory properties such as chromaticity and physical properties [36,37]. In this study, the addition of wheat fiber and oat fiber to the batter was concluded to be a suitable ingredient to enhance the sensory traits, as they had the highest score in

Table 4. Sensory evaluation of fried pork loin formulated with various type of dietary fiber

\begin{tabular}{|c|c|c|c|c|c|}
\hline \multirow{2}{*}{ Traits } & \multicolumn{4}{|c|}{ Treatment } & \multirow{2}{*}{ SEM } \\
\hline & Control & WF & BF & OF & \\
\hline Color & $8.50^{b}$ & $9.22^{\mathrm{a}}$ & $8.50^{\mathrm{b}}$ & $9.56^{a}$ & 0.12 \\
\hline Flavor & $8.67^{b}$ & $9.44^{\mathrm{a}}$ & $8.78^{\mathrm{ab}}$ & $9.33^{\mathrm{ab}}$ & 0.13 \\
\hline Texture & $8.78^{\mathrm{c}}$ & $9.00^{\mathrm{ab}}$ & $8.22^{\mathrm{bc}}$ & $9.00^{\mathrm{a}}$ & 0.15 \\
\hline Juiciness & $8.78^{\mathrm{ab}}$ & $9.00^{\mathrm{a}}$ & $8.11^{b}$ & $9.00^{\mathrm{a}}$ & 0.13 \\
\hline Off-flavor & 9.00 & 9.33 & 9.13 & 9.29 & 0.11 \\
\hline Overall acceptability & $8.56^{\mathrm{b}}$ & $9.22^{\mathrm{a}}$ & $8.44^{\mathrm{b}}$ & $9.33^{\mathrm{a}}$ & 0.12 \\
\hline
\end{tabular}

All data shown as mean.

${ }^{a-c}$ Means on the same row with different letters are significantly different $(p<0.05)$.

Control, batter without dietary fiber; WF, batter with wheat dietary fiber; BF, batter with bamboo dietary fiber; OF, batter with oat dietary fiber. 
the sensory evaluation among the dietary fibers evaluated.

\section{CONCLUSION}

This study aimed to investigate the effect of various dietary fibers (extracted from wheat, bamboo, and oat) added to the batter for fried pork loin. The addition of dietary fiber simultaneously increased the water content and decreased the fat content. The viscosity, coating yield, and frying yield were shown to be excellent characteristics with the addition of dietary fiber. The sensory evaluation of the wheat fiber and oat fiber treatments were excellent in comparison to the other treatments. Although the CIE color and aroma principal components of the wheat fiber treatment were similar to those of the control, those of the oat fiber treatment were distinct. Overall, wheat and oat fiber are suitable additions to fried pork loin batter to decrease the fat content and improve the quality. Moreover, using wheat fiber results in characteristics similar to those of regular fried pork loin; in contrast, using oat fiber results in distinct characteristics from those of the regular fried pork loin.

\section{REFERENCES}

1. Resurreccion AVA. Sensory aspects of consumer choices for meat and meat products. Meat Sci. 2004;66:11-20. https://doi.org/10.1016/S0309-1740(03)00021-4

2. Saguy IS, Dana D. Integrated approach to deep fat frying: engineering, nutrition, health and consumer aspects. J Food Eng. 2003;56:143-52. https://doi.org/10.1016/S02608774(02)00243-1

3. Higgs JD. The changing nature of red meat: 20 years of improving nutritional quality. Trends Food Sci Tech. 2000;11:85-95. https://doi.org/10.1016/S0924-2244(00)00055-8

4. Mellema M. Mechanism and reduction of fat uptake in deep-fat fried foods. Trends Food Sci Tech. 2003;14:364-73. https://doi.org/10.1016/S0924-2244(03)00050-5

5. Sanchez-Muniz FJ, Viejo JM, Medina R. Deep-frying of sardines in different culinary fats. Changes in the fatty acid composition of sardines and frying fats. J Agric Food Chem. 1992;40:2252-6. https://doi.org/10.1021/jf00023a039

6. Fiszman S, Sanz T. Battering and breading: principles and system development. In: Guerrero-Legarreta I, editor. Handbook of poultry science and technology. Hoboken, NJ: John Wiley \& Sons; 2010. p. 5-45.

7. Willett WC, Ascherio A. Trans fatty acids: are the effects only marginal? Am J Public Health. 1994;84:722-4. https://doi.org/10.2105/AJPH.84.5.722

8. White JDPJ, Feldman EB. Saturated and hydrogenated fats in food on relation to health.J Am Coll Nutr. 1991;10:577-92. https://doi.org/10.1080/07315724.1991.10718180

9. Roberfroid M. Dietary fiber, inulin, and oligofructose: a review comparing their physiological effects. Crit Rev Food Sci. 1993;33:103-48. https://doi.org/10.1080/10408399309527616

10. Brown L, Rosner B, Willett WW, Sacks FM. Cholesterol-lowering effects of dietary fiber: a meta-analysis. Am J Clin Nutr. 1999:69:30-42. https://doi.org/10.1093/ajcn/69.1.30

11. Biswas AK, Kumar V, Bhosle S, Sahoo J, Chatli MK. Dietery fibers as functional ingredients in meat products and their role in human health. Int J Livest Prod. 2011;2:45-54. https://doi. org/10.5897/IJLP.9000007

12. Abdul-Hamid A, Luan Y. Functional properties of dietary fibre prepared from defatted rice bran. Food Chem. 2000;68:15-9.

13. Keeton JT, Eddy S. Chemical and physical characteristics of meat. In: Jensen WK, Devine C, 
Dikeman M, editors. Encyclopedia of meat sciences. Amsterdam, Nederland: Elsevier; 2004. p. 210-65.

14. Adedeji AA, Ngadi MO. Microstructural properties of deep-fat fried chicken nuggets coated with different batter formulation. Int J Food Prop. 2011;14:68-83. https://doi. org/10.1080/10942910903131423

15. AOAC [Association of Official Analytical Chemists] International. Official methods of analysis of AOAC International. 15th ed. Washington, DC: AOAC International; 1990.

16. Grunert KG. Future trends and consumer lifestyles with regard to meat consumption. Meat Sci. 2006;74:149-60. https://doi.org/10.1016/j.meatsci.2006.04.016

17. Park SY, Oh TS, Kim GW, Kim HY. Qaulity properties of various dietary fibers as isolated soy protein (ISP) replacements in pork emulsion systems. J Anim Sci Technol. 2020;62:94-102. https://doi.org/10.5187/jast.2020.62.1.94

18. Grigelmo-Miguel N, Martin-Belloso O. Peach dietary fiber as a food ingredient. In: Book of abstracts: Institute of Food Technologists Annual Meeting; 1997; Orlando, FL.

19. Ang JF, Miller WB, Blais IM. Fiber additives for frying batters. United States patent US5019406.1991 May 28.

20. Huff-Lonergan E, Lonergan SM. Mechanisms of water-holding capacity of meat: the role of postmortem biochemical and structural changes. Meat Sci. 2005;71:194-204. https://doi. org/10.1016/j.meatsci.2005.04.022

21. Choi YS, Park KS, Kim HW, Hwang KE, Song DH, Choi MS, et al. Quality characteristics of reduced-fat frankfurters with pork fat replaced by sunflower seed oils and dietary fiber extracted from makgeolli lees. Meat Sci. 2013;93:652-8. https://doi.org/10.1016/j.meatsci.2012.11.025

22. Choi SI, Kim TJ, Park JH, Lim CS, Kim MY. Quality characteristics of frying mix added with brown rice fiber. Korean J Food Cookery Sci. 2011;27:671-80. https://doi.org/10.9724/ kfcs.2011.27.6.671

23. Sosulski FW, Wu KK. High-fiber breads containing field pea hulls, wheat, corn and wild oat brans. Cereal Chem 1988;65:186-91.

24. Choi SI, Kim TJ, Park JH, Lim CS, Kim MY. Quality characteristics of frying mix added with brown rice fiber. Korean J Food Cookery Sci. 2011;27:671-80. https://doi.org/10.9724/ kfcs.2011.27.6.671

25. Pérez-Jiménez J, Díaz-Rubio ME, Mesías M, Morales FJ, Saura-Calixto F. Evidence for the formation of maillardized insoluble dietary fiber in bread: a specific kind of dietary fiber in thermally processed food. Food Res Int. 2014;55:391-6. https://doi.org/10.1016/ j.foodres.2013.11.031

26. Pinthus EJ, Weinberg P, Saguy IS. Gel-strength in restructed potato products affets oil uptake during deep-fat frying. J Food Sci. 1992;57:1359-60. https://doi.org/10.1111/j.13652621.1992.tb06857.x

27. Mckee LH, Latner TA. Underutilized sources of dietary fiber: a review. Plant Food Hum Nutr. 2000;55:285-304. https://doi.org/10.1023/A:1008144310986

28. Cunningham FE, Tiede LM. Influence of batter viscosity on breading of chicken drumsticks. J Food Sci. 1981;46:1950. https://doi.org/10.1111/j.1365-2621.1981.tb04527.x

29. Akdeniz N, Sahin S, Sumnu G. Functionality of batters containing different gums for deep-fat frying of carrot slices. J Food Eng. 2006;75:522-6. https://doi.org/10.1016/j.jfoodeng.2005.04.035

30. Dogan SF, Sahin S, Sumnu G. Effects of soy and rice flour addition on batter rheology and quality of deep-fat fried chicken nuggets. J Food Eng. 2005;71:127-32. https://doi. org/10.1016/j.jfoodeng.2004.10.028 
31. Sahin S, Sumnu G, Altunakar B. Effects of batters containing different gum types on the quality of deep-fat fried chicken nuggets. J Sci Food Agric. 2005;85:2375-9. https://doi. org/10.1002/jsfa.2258

32. Meyers MA, Grazela A. Chapter 7 - Functionality of hydrocolloids in batter coating systems. In: Kulp K, Loewe R, Lorenz K, Gelroth J, editors. Batters and breadings in food procissing. Saint Paul: AACC International; 1990. p. 117-38.

33. Park SY, Seol KH, Kim HY. Effect of dry-aged beef crust levels on quality properties of brown sauce. Food Sci Anim Resour. 2020;40:699-709. https://doi.org/10.5851/kosfa.2020.e45

34. Thomas R, Jebin N, Barman K, Das A. Quality and shelf life evaluation of pork nuggets incorporated with fermented bamboo shoot (Bambusa polymorpha) mince. Meat Sci. 2014;96:1210-8. https://doi.org/10.1016/j.meatsci.2013.10.035

35. Zeng H, Chen J, Zhai J, Wang H, Xia W, Xiong YL. Reduction of the fat content of battered and breaded fish balls during deep-fat frying using fermented bamboo shoot dietary fiber. LWT Food Sci Technol. 2016;73:425-31. https://doi.org/10.1016/j.lwt.2016.06.052

36. Fernández-Ginées JM, Fernández-López J, Sayas-Barberá E, Sendra E, Pérez-Álvarez JA. Lemon albedo as a new source of dietary fiber: application to bologna sausages. Meat Sci. 2004;67:7-13. https://doi.org/10.1016/j.meatsci.2003.08.017

37. Steenblock RL, Sebranek JG, Olson DG, Love JA. The effects of oat fiber on the properteis of light bologna and fat-free frankfurters. J Food Sci. 2001;66:1409-15. https://doi.org/10.1111/ j.1365-2621.2001.tb15223.x 